Received Date : 29-Apr-2015

Revised Date : 24-Aug-2015

Accepted Date : 31-Aug-2015

Article type : Original Research

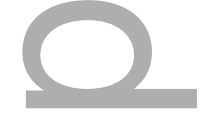

\title{
Protein Biomarkers and Microbial Profiles in Peri-Implantitis
}

Hom-Lay Wang D.D.S., PhD.*, Carlos Garaicoa-Pazmino D.D.S.*, Amy Collins B.Sc. *, Hwen-Sei Ong D.D.S*, Rini Chudri D.D.S *, William V. Giannobile D.D.S., MS, DMSc *

* Department of Periodontics and Oral Medicine, University of Michigan School of Dentistry, Ann Arbor, MI, USA.

Disclaimers: The authors do not have any financial interests, either directly or indirectly, in the products or information listed in the paper.

\section{Corresponding author:}

Hom-Lay Wang, DDS, MSD, PhD

Department of Periodontics and Oral Medicine, University of Michigan School of Dentistry

1011 North University Avenue

Ann Arbor, Michigan 48109-1078, USA.

TEL: (734) 763-3383; FAX: (734) 936-0374

E-mail address: homlay@umich.edu

Word count: 3066

Tables and figures: 5 Tables and 1 Figure

Running title: Protein Biomarkers and Microbial Profile in Peri-implantitis

Summary: Peri-implant crevicular fluid (PICF)-derived biomarkers combined with sitespecific microbial profile have potential as possible predictors for the onset of periimplant diseases.

This is the author manuscript accepted for publication and has undergone full peer review but has not been through the copyediting, typesetting, pagination and proofreading process, which may lead to differences between this version and the Version of Record. Please cite this article as doi: 10.1111/clr.12708

This article is protected by copyright. All rights reserved 
Key words: peri-implant disease, peri-implant cervicular fluid, dental implant microbiology, and salivary diagnostics

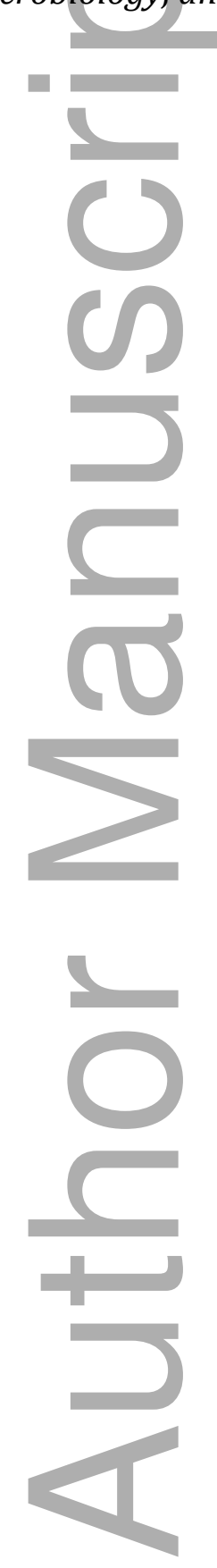

This article is protected by copyright. All rights reserved 


\section{Abstract}

Objectives: The aim of the present investigation was to determine the profile of periimplant crevicular fluid (PICF) biomarkers combined with microbial profiles from implants with healthy peri-implant tissues and peri-implantitis to assess real-time disease activity.

Material and Methods: Sixty-eight patients were included in this cross-sectional study. They were divided into two groups: 34 patients with at least one healthy implant (control) and 34 with at least one peri-implantitis affected implant (test). Total DNA content and qPCR analysis for periodontal bacteria obtained from subgingival plaque samples (Aggregatibacter actinomycetemcomitans, Prevotella intermedia, Porphyromonas gingivalis, Tannerella forsythia, and Treponema denticola) and a PICF analysis for IL-1 $\beta$, VEGF, MMP-8, TIMP-2 and OPG were performed. The individual and combined diagnostic ability of each biomarker for peri-implantitis and target bacterial species were analyzed.

Results: The mean concentration of IL-1 $\beta$ (44.6 vs $135.8 \mathrm{pg} / \mathrm{ml}$; p<0.001), TIMP-2 (5488.3 vs 9771.8 pg/ml; p=0.001), VEGF (59.1 vs 129.0 pg/ml; p=0.012) and OPG (66.5 vs $111.7 \mathrm{pg} / \mathrm{ml} ; \mathrm{p}=0.050$ ) were increased in the peri-implantitis patients. The mean expression of MMP-8 (6029.2 vs $5943.1 \mathrm{pg} / \mathrm{ml}$; $\mathrm{p}=0.454$ ) and did not reveal a meaningful difference among groups. Total bacterial DNA of selected microorganisms was associated with a 3 fold or greater increase in peri-implantitis although no statistical significant difference. The ability to diagnose diseased sites was enhanced by T. denticola combined with IL-1 $\beta$, VEGF and TIMP-2 PICF levels.

Conclusion: The present data suggest that the increased levels of the selected PICFderived biomarkers of periodontal tissue inflammation, matrix degradation/regulation and alveolar bone turnover/resorption combined with site-specific microbial profiles may be associated with peri-implantitis and could have potential as predictors of periimplant diseases.

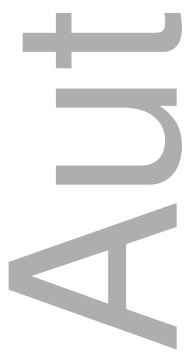

\section{Introduction}

This article is protected by copyright. All rights reserved 
Current clinical periodontal diagnostic criteria used in the practice setting have limited utility to predict future disease progression (Ramseier et al., 2009). The potential role of host-response and microbial biomarkers obtained from oral-fluids have been investigated and used as complementary diagnostic tools for periodontal disease. Concentrations of host-response molecules may represent a more accurate, real-time disease activity than conventional clinical measurements (Syndergaard et al., 2014, Sexton et al., 2011).

Microbial communities from subgingival and supragingival biofilm have been clustered in complexes according by their relationship to commonly used clinical parameters (Haffajee et al., 2008, Socransky et al., 1998). Red complex bacteria (Porphyromonas gingivalis, Tannerella forsythia, and Treponema denticola) and orange complex member (Prevotella intermedia) have been pointed out as the species responsible for chronic periodontitis (Kigure et al., 1995, Gmur et al., 1989), while Aggregatibacter actinomycetemcomitans for aggressive periodontitis (Mandell, 1984). Furthermore, besides being highly associated with disease, assessments of microbiological presence and load are able to predict its progression in susceptible sites (Teles et al., 2010, Saygun et al., 2011, Charalampakis et al., 2013). Interestingly, the pairing of both data has proven valuable to increase their diagnostic abilities in cross-sectional and longitudinal models in subjects afflicted with periodontitis (Ramseier et al., 2009, Kinney et al., 2011, Kinney et al., 2014, Salcetti et al., 1997). Conversely, limited information regarding the usefulness of biomarkers upon periimplantitis is currently available.

The imbalance between the bacterial challenge and host response at the soft tissue-implant interface triggers an inflammatory process different from those observed around natural teeth in chronic periodontitis (Carcuac et al., 2013). Peri-implantitis by definition has been described as an inflammatory reaction associated with the loss of supporting bone beyond initial biological bone remodeling around an implant in function, and is commonly reported as one of the major contributors of implant failure (Roos-Jansaker et al., 2006, Zitzmann and Berglundh, 2008, American Academy of Periodontology, 2013), and associated with both periodontal and non-periodontal pathogens (Tamura et al., 2013, Kumar et al., 2012, Mombelli and Decaillet, 2011). 
Radiographic and clinical assessments such as radiographic bone loss evaluation, peri-implant probing, bleeding on probing (BOP), microbial testing, implant mobility and suppuration all serve as traditional measuring tools for peri-implant surveillance and disease diagnosis (Heitz-Mayfield, 2008). Moreover, an increasing interest for the assessment of numerous inflammatory mediators, host proteolytic enzymes and tissue breakdown biomarkers, in addition to angiogenic and matrix metalloproteinase inhibitors biomarkers within gingival crevicular fluid (GCF) and peri-implant crevicular fluid (PICF) has been targeted for disease detection and prediction in order to elucidate a broad overview of the different phases of the periodontal and peri-implant diseases (Melo et al., 2012, Nowzari et al., 2012, Kivela-Rajamaki et al., 2003, Nomura et al., 2000, Arikan et al., 2011, Booth et al., 1998, Cornelini et al., 2001, Chen et al., 2007, Soell et al., 2002).

Identifying a single predictive biomarker for periodontal and peri-implant diseases would be of great significance. However, microbial profiles and a combination of several host-response biomarkers around dental implants could reveal a more precise assessment of a disease status than traditional clinical measurements as observed in a periodontitis model (Ramseier et al., 2009, Kinney et al., 2014). Therefore, the aim of the present cross-sectional study was to determine the profile of selected PICF-derived biomarkers combined with microbial profiles associated with healthy and peri-implantitits-affected implants.

\section{Material and Methods}

Subject selection

This clinical study was approved by the University of Michigan Health Science Institutional Review Board (HUM00042258). Research subjects were recruited from new or active patients receiving dental care at the University of Michigan School of Dentistry from April 2012 through February 2013.

To be eligible for this study, partially edentulous patients must have at least one implant with healthy peri-implant tissues (control group) or periimplantitis (test group) using a standard implant placement or in conjunction with guided bone regeneration procedures supporting either a fixed or 
removable and a cemented or screwed-retained prosthesis in function for at least 6 months. If a patient possessed more than one implant, data were collected only from either the least or more affected single implant. Following the American Academy of Periodontology guidelines (American Academy of Periodontology, 2013), a healthy implant site was considered to be absent of radiographic implant threads exposure. Peri-implantitis-affected site displayed bleeding on probing (BOP) and/or suppuration in combination with PPD $\geq 5 \mathrm{~mm}$ and radiographic bone loss with the exposure of the implant surface below the first thread based on a peri-apical radiograph. Patients with the following characteristics were excluded: 1) uncontrolled systemic disease or condition to alter bone metabolism (i.e; osteoporosis, osteopenia, hyperparathyroidism or Paget's disease); 2) pregnancy; 3) history of oral cancer, sepsis or adverse outcomes to oral procedures; 4) long-term use of antibiotics ( $>2$ weeks in the past two months); 5) patients taking medications known to modify bone metabolism (i.e., bisphosphonates, corticosteroids, hormone replacement therapy); or 6) previous treatment for peri-implantitis. Based on the inclusion/exclusion criteria, 68 patients with implants placed in both maxilla and mandible were eligible for this study. All subjects signed a written informed consent to be part of the study.

After assessing eligibility for the study, extraoral, intraoral and radiographic evaluations were documented. Digital and film-based radiographic examination from standardized peri-apical radiographs with a parallel technique in order to analyze the bone loss from the Implant-Fixture-Level to the bone crest. Clinical measurements included PPD, BOP (+/-), Mobility (+/-) and Suppuration (+/-). Patients were asked about their smoking habits and divided into three groups: 1) never smoked, 2) past smoker or 3) current smoker.

The clinical examination was performed by two calibrated examiners (HW and HC) using the kappa statistic (0.76) as a reference for calibration.

\section{Sample collection}

Subgingival plaque biofilm was collected from the mesio-buccal aspect of the healthy implant site and the deepest implant site of the disease implant. The PICF samples were collected from the same healthy and diseased implant sites 
that fulfill the inclusion criteria to establish a correlation between microbial profiles.

Each implant-crown was dried with sterile gauze and the supragingival plaque was removed. The area was dried with a gentle blast of air and the supragingival/supramucosal plaque was carefully removed. A sterile paper point was inserted apically until resistance was felt at the base of the sulcus/pocket for plaque sampling around implants. The samples were immediately placed into labeled vials containing $500 \mu \mathrm{l}$ of stabilizing buffer* to prevent mRNA degradation during transportation and shaken for $10 \mathrm{sec}$. The samples were then vortexed for approximately 30 seconds, placed onto dry ice for transport to the laboratory and stored in a $-80^{\circ} \mathrm{C}$ freezer until analysis. PICF samples were collected using methylcellulose strips PerioPaper ${ }^{\dagger}$ gently placed into the cleansed and dried pocket for 1 minute, transferred into separate microfuge tubes and stored in a $\quad-80^{\circ} \mathrm{C}$ freezer until analysis.

Plaque and target bacterial DNA isolation

Plaque samples absorbed onto paper points were vortexed in Eppendorf tubes ${ }^{\circledR} \neq$ to suspend the plaque. The paper points were then removed and the tubes centrifuged to pellet bacteria. Total DNA from the plaque samples was purified using the MasterPure ${ }^{\mathrm{TM}}$ Complete DNA and RNA Purification Kit $\S$ according to the instructions of the manufacturer. Total DNA from the target bacterial species (A. actinomycetemcomitans, $P$. intermedia, P. gingivalis, T. forsythia, and T. denticola) was used as standards, and purified from mid-log phase cultures using same procedure as the plaque samples. The concentrations of standard bacterial DNA were adjusted to $100 \mu \mathrm{g} / \mathrm{ml}$ in water and prepared as four additional serial dilutions (1:10). Genomic DNA was stored at $4^{\circ} \mathrm{C}$ until used. qPCR analysis

A standard curve was performed using $1 \mathrm{ul} /$ sample of each dilution and primers specific to their respective 16S rRNA gene sequences. Amplification primers from a universal prokaryotic set and 16S rRNA gene sequences of the

\footnotetext{
${ }^{*}$ RNAprotect ${ }^{\mathrm{TM}}$, Ambion, Austin, TX, USA

† Oralflow Inc., Smithtown, NY, USA

* Eppendorf AG, Hamburg, Germany

$\S$ Epicentre Biotechnologies, Madison, WI, USA
} 
target bacteria were synthesized according to published sequences (Shelburne et al., 2008, Mullally et al., 2000). Quantitative Polymerase Chain Reaction (qPCR) was performed using SYBR® Green PCR Master Mix $\|^{* *}$ and assayed in an ABI 7700 Sequence Detector with 40 cycles. $29 \mathrm{ul}$ of a master mix containing primer was added to the wells of a 96-well assay plate with 1ul/DNA for each standard dilution and $2 \mathrm{ul}$ of each plaque sample were then assayed for each of the target bacterial primers and the universal primer as described above. DNA content was calculated from the above standard curves. The percentage of total flora for each species was calculated by dividing the amount of target DNA by the total amount of bacterial DNA determined by qPCR with the universal primer. Standard curves were generated from Ct values proportional to the starting number of gene copies. The standard curve for the universal primer was generated in the same manner using genomic DNA from $P$. gingivalis.

Peri-implant Crevicular Fluid analysis

A $20 \mu \mathrm{l}$ extraction solution containing $/ \mathrm{g} / \mathrm{al}$ aprotinin, $1 \mathrm{mM}$ phenylmethylsulfonyl fluoride, and $0.1 \%$ human serum albumin in phosphatebuffered saline (PBS, pH 7.4) was pipetted directly onto the cellulose portion of each PerioPaper $\AA^{\circledR}$ strip and secured at the top of a $12 \times 75 \mathrm{~mm}$ polystyrene culture tube using a cap to hold it in place. After centrifugation at 2,000 rpm at $4^{\circ} \mathrm{C}$ for $5 \mathrm{~min}$, each strip was washed five times to yield a total elution volume of $100 \mu \mathrm{l}$. The samples were stored at $-80^{\circ} \mathrm{C}$ until the antibody array quantification. The samples were thawed and added to the arrays according to the manufacturer's protocol, which included recombinant protein standards for standard curve generation, and the slides were scanned and measured for fluorescent signal intensity, and data were imported to RayBiotech® Antibody Array software for statistical analysis.

Quantitative assessments of biomarker expression in PICF samples were performed using custom human Quantibody® arrays $\rrbracket_{\cdot}+$ Targeted biomarkers included pro-inflammatory and angiogenic biomarkers, Interleukin-1 beta (IL$1 \beta$ ), vascular endothelial growth factor (VEGF), tissue resorptive matrix metalloproteinase-8 (MMP-8) and tissue inhibitor of metalloproteinase-2 (TIMP-

|| Life Technologies, Carlsbad, CA, USA

I RayBiotech, Inc., Norcross, GA, USA

This article is protected by copyright. All rights reserved 
2) and levels of bone turnover biomarker, osteoprotegerin (OPG).

\section{Statistical Analysis}

Basis demographics were summarized including mean values for clinical and radiographic parameters; selected biomarkers levels and mean percentage of total bacterial DNA were calculated for each sampled implant site. Parameter comparisons between control and test groups sample were performed using non-parametric Mann-Whitney U test and Two-proportion z-test. A statistical significance difference was set at a p-value of 0.05 and further analysis with the Bonferroni correction for multiple comparisons. The biomarker levels were dichotomized as being high (above) or low (below) using the median as threshold to determine the diagnostic ability of each of the variables. Odds ratios were used to determine odds of disease onset using $2 \times 2$ contingency table resulting from dichotomizing the median levels of the selected biomarkers in respect to their healthy or disease status. The individual and combined effect of being high was analyzed for each biomarker and target bacterial species.

\section{Results}

Sixty-eight total patients were recruited and divided into two categories according the disease status. Overall, thirty-five males (51.46\%) and thirty-three females (48.52\%) with an average age of 63.74 years (age range: 37 and 83 years) were enrolled in the present study. A total of 34 implants were included in the healthy group while 34 implants diagnosed with peri-implantitis were included in the test group.

Collected measurements at the implant level and demographic data are summarized on Table 1. Statistical analysis revealed a significant difference (SSD) between groups in mean BOP (5.39\% vs 72.05\%; $\mathrm{p}<0.001)$, mean PPD $(3.17 \mathrm{~mm}$ vs. $5.84 \mathrm{~mm}$; $\mathrm{p}<0.001)$ and mean BL $(0.06 \mathrm{~mm}$ vs. $2.81 \mathrm{~mm}$; $\mathrm{p}=0.049)$. The prevalence of smoking status was lower in the healthy group when compared to the peri-implantitis group ( $0 \%$ vs. $5.88 \%$ ); however, no further analysis was performed due confounded data and unequal distribution.

The mean levels of the selected-PICF biomarkers for both healthy and peri-implantitis groups are shown in Figure 1. Concentrations levels of IL-1 $\beta$ 
(44.60 vs 135.83 pg/ml; p<0.001), TIMP-2 (5488.32 vs 9771.82 pg/ml; p=0.001), VEGF (59.11 vs $128.99 \mathrm{pg} / \mathrm{ml} ; \mathrm{p}=0.012$ ) and OPG (66.51 vs $111.69 \mathrm{pg} / \mathrm{ml}$; $\mathrm{p}=0.050$ ) were increased in the peri-implantitis affected implants (Table 2). The expression levels of MMP-8 (6029.18 vs 5943.13 pg/ml; p=0.454) failed to reveal a meaningful difference among groups. As depicted in Table 3, the comparative microbial analysis revealed a 3-fold increase or more in peri-implantitis; however, no statistical significant difference was found.

The individual diagnostic ability of the selected biomarkers and targeted microorganisms are shown in Table 4. MMP-8 and OPG individual effects were not considered due to failure to show an initial statistical significant difference of $\mathrm{p}<0.05$. IL-1 $\beta$ demonstrated significant high ability (odds ratio $[\mathrm{OR}]=7.71$; $\mathrm{p}=0.002$ ) for the prediction of a disease status followed by and with a lesser impact, TIMP-2 (OR = 4.37; $\mathrm{p}=0.004)$ and VEGF (OR = 2.60; $\mathrm{p}=0.054)$. A notable effect was observed only from $T$. denticola $(\mathrm{OR}=4.57 ; \mathrm{p}=0.010)$ and lesser impact from $T$. forsythia $(\mathrm{OR}=1.80 ; \mathrm{p}=0.226)$ and $P$. gingivalis $(\mathrm{OR}=1.12$; $\mathrm{p}=0.808)$

Combinations of the PICF biomarkers and targeted microorganisms were performed to identify greater diagnostic abilities. Table 5 showed that $T$. denticola proved to enhance the diagnostic ability of disease sites when combined with IL-1 $\beta$ and VEGF and TIMP-2. Interestingly, the OR of these combinations showed an increased effect when compared to their individual counterparts except for IL-1 $\beta$ alone.

\section{Discussion}

A myriad of reports suggested a value of PICF-derived biomarker expression levels for periodontal and peri-implant disease detection (Nowzari et al., 2012, Murata et al., 2002, Ma et al., 2000, Xu et al., 2008, Guncu et al., 2012, Di Alberti et al., 2013). A series of studies using the same patient population have demonstrated the usefulness and remarked the advantageous impact of oral fluids in a clinical setting. Ramseier and colleagues observed in a cross sectional study an augmented diagnostic ability of salivary biomarkers when combined with bacterial profiles on subjects with periodontal disease (Ramseier et al., 2009). Furthermore, a longitudinal periodontal disease-monitoring study 
combined with a non-treatment phase was able to recognize clusters of hostresponse biomarkers and pathogens highly associated with periodontal breakdown (Kinney et al., 2011). Ultimately, the potential of saliva and GCF were confirmed to accurately identify periodontal disease activity and its response to non-surgical therapy (Kinney et al., 2014).

A comprehensive analysis of the individual diagnostic ability of the selected biomarkers and targeted microorganisms was performed. IL-1 $\beta$ demonstrated significant high ability (odds ratio $[\mathrm{OR}]=7.71$ ) for the prediction of a disease status followed by and with a lesser impact, TIMP-2 (OR $=4.37)$ and VEGF (OR = 2.60). Certainly, increased GCF and PICF volume and expression levels of these biomarkers may reflect an early inflammatory event in process. Implant exposure to biofilm accumulation had shown lower and nearly significant IL-1 $\beta$ levels when compared to teeth after a 21-day period (Schierano et al., 2008). Conversely, Salvi and colleagues found a stronger inflammatory response around implants after 6-week period of experimental peri-mucositis (Salvi et al., 2012). On the other hand, our data was unable to accurately determine bone osteoclastic activity, whereas such finding would be more meaningful as inflammation can be detected by simple visual inspection. It should be noted that high expression levels of MMP-8 often correlate with active osteoclastic activity in both periodontitis progression and peri-implant lesions (Miller et al., 2006, Kivela-Rajamaki et al., 2003, Ramseier et al., 2009, Salvi et al., 2012).

Predominance of periodontopathic Gram-negative bacteria in subgingival biofilm has been reported around implants (Mombelli and Decaillet, 2011). In our study, none of the targeted microorganisms revealed a more limited association with peri-implantitis. The individual diagnostic ability was significantly higher for $T$. denticola $(\mathrm{OR}=4.57)$ when compared to any other of the targeted microorganisms. Early reports have addressed $P$. nigrescens, $P$. micros and F. nucleatum sp associated with failing implants and responding to patient susceptibility (Salcetti et al., 1997). As a matter of fact, microbial profiles around diseased implants have shown heterogeneous and complex environments significantly different from those observed in periodontitis (Albertini et al., 2014, Kumar et al., 2012). Moreover, these communities might 
not be reserved only for specific periodontal pathogens and patient susceptibility, but instead, respond to bacterial adaptation and selection (Dabdoub et al., 2013).

PICF biomarkers and targeted microorganisms were clustered in order to identify greater disease association. It was pointed out that each biomarker when analyzed individually and disassociated with a microbial profile have shown low sensitivity and high specificity values, thus, weakening its disease predictive value (Kinney et al., 2014). Salcetti and coworker identified a correlation of elevated prostaglandin-2 (PG2) levels and greater detection frequencies of $P$. nigrescens and P. micros providing additional diagnostic ability around failing implants (Salcetti et al., 1997). Our data reported a stronger diagnostic ability from T. denticola when combined with IL-1 $\beta$ and TIMP-2 and VEGF, in fact, slightly more than powerful than their individual counterparts. Conversely, the Bonferroni correction was used to control the familywise error rate and reduce the probability to make one or more type I error and showing no statistical significant difference among the clustered variables. MMP-8 and OPG disease-diagnostic accuracy has been addressed to increase when combined with a microbial profile suggesting its true potential to predict future disease progression in periodontitis (Ramseier et al., 2009, Salminen et al., 2014), however, this effect was not observed within the present peri-implantitis patients.

Current disease criteria for establishing peri-implantitis status are primarily based upon clinical and radiographic measurements. PPD, BOP and radiographic $\mathrm{BL}$ seem insufficient to formulate an accurate diagnosis and significantly affected by the implant-supported prosthesis. Tomasi and colleagues identified numerous conflicting reports using different thresholds to determine radiographic bone loss around dental implants in an attempt to evaluate the prevalence and treatment outcomes of peri-implantitis (Tomasi and Derks, 2012). The need of baseline and longitudinal data is required for a clearer understanding of the disease (American Academy of Periodontology, 2013, Froum and Rosen, 2012). Protein biomarkers and microbial assessment around implants could supply additional information on the biological status at the periimplant site. Furthermore, to the present day there is no definitive 
reconstructive or non-reconstructive evidence-based treatment for periimplantitis (Khoshkam et al., 2013, Figuero et al., 2014, Smeets et al., 2014).

Modern oral health professionals are in the need of diagnostic and prognostic tools to obtain fast and valuable information in order to enhance the decision-making for both periodontal and implant therapy (Giannobile et al., 2009, Agrawal et al., 2012). Nevertheless, present diagnostic tests require training, major resources and increased cost-effective healthcare delivery (Giannobile, 2012). For that reason, biomarkers assessment with portable and simpler microfluidic screening devices might lead to acceptance from the dental community and a more efficient therapy (Yager et al., 2006, Giannobile et al., 2011).

Within the limitations of the present study, these data suggest that the selected PICF-derived biomarkers of periodontal tissue inflammation, matrix degradation/regulation and alveolar bone turnover/resorptive combined with site-specific microbial profile may be associated with peri-implant diseases. Prospective and longitudinal clinical human trials are necessary to evaluate the diagnostic ability of these variables in order to provide valuable information regarding disease progression in peri-implant mucosistis or peri-implantitis.

\section{Acknowledgements}

This study was supported by the University of Michigan Periodontal Graduate Student Research Fund. The authors would like to acknowledge the laboratory and clinical assistance of Hsun-Liang Chan, James V. Sugai, Erin Heffez, Fernando Suarez and Alberto Monje. We appreciate Dr. Qiming Jin for the preparation of figures and Dr. Lena Larsson for her assistance during the preparation of the present article.

This article is protected by copyright. All rights reserved 


\section{References}

Agrawal, P., Sanikop, S. \& Patil, S. (2012) New developments in tools for periodontal diagnosis. International dental journal 62, 57-64. doi:10.1111/j.1875-595X.2011.00099.x.

Albertini, M., Lopez-Cerero, L., O'Sullivan, M. G., Chereguini, C. F., Ballesta, S., Rios, V., Herrero-Climent, M. \& Bullon, P. (2014) Assessment of periodontal and opportunistic flora in patients with peri-implantitis. Clinical oral implants research. doi:10.1111/clr.12387.

American Academy of Periodontology (2013) Peri-implant mucositis and periimplantitis: a current understanding of their diagnoses and clinical implications. Journal of periodontology $\mathbf{8 4}, \quad 436-443$. doi:10.1902/jop.2013.134001.

Arikan, F., Buduneli, N. \& Lappin, D. F. (2011) C-telopeptide pyridinoline crosslinks of type I collagen, soluble RANKL, and osteoprotegerin levels in crevicular fluid of dental implants with peri-implantitis: a case-control study. The International journal of oral \& maxillofacial implants 26, 282289.

Booth, V., Young, S., Cruchley, A., Taichman, N. S. \& Paleolog, E. (1998) Vascular endothelial growth factor in human periodontal disease. Journal of periodontal research 33, 491-499.

Carcuac, O., Abrahamsson, I., Albouy, J. P., Linder, E., Larsson, L. \& Berglundh, T. (2013) Experimental periodontitis and peri-implantitis in dogs. Clinical oral implants research 24, 363-371. doi:10.1111/clr.12067.

Charalampakis, G., Dahlen, G., Carlen, A. \& Leonhardt, A. (2013) Bacterial markers vs. clinical markers to predict progression of chronic periodontitis: a 2-yr prospective observational study. European journal of oral sciences 121, 394-402. doi:10.1111/eos.12080.

Chen, D., Wang, Q., Ma, Z. W., Chen, F. M., Chen, Y., Xie, G. Y., Wang, Q. T. \& Wu, Z. F. (2007) MMP-2, MMP-9 and TIMP-2 gene polymorphisms in Chinese patients with generalized aggressive periodontitis. Journal of clinical periodontology 34, 384-389. doi:10.1111/j.1600-051X.2007.01071.x.

Cornelini, R., Artese, L., Rubini, C., Fioroni, M., Ferrero, G., Santinelli, A. \& Piattelli, A. (2001) Vascular endothelial growth factor and microvessel density 
around healthy and failing dental implants. The International journal of oral \& maxillofacial implants 16, 389-393.

Dabdoub, S. M., Tsigarida, A. A. \& Kumar, P. S. (2013) Patient-specific analysis of periodontal and peri-implant microbiomes. Journal of dental research 92,

168S-175S. doi:10.1177/0022034513504950.

Di Alberti, L., Rossetto, A., Albanese, M., D'Agostino, A., De Santis, D., Bertossi, D. \& Nocini, P. F. (2013) Expression of Vascular Endothelial Growth Factor (VEGF) mRNA in healthy bone tissue around implants and in periimplantitis. Minerva stomatologica.

Figuero, E., Graziani, F., Sanz, I., Herrera, D. \& Sanz, M. (2014) Management of peri-implant mucositis and peri-implantitis. Periodontology 2000 66, 255273. doi:10.1111/prd.12049.

Froum, S. J. \& Rosen, P. S. (2012) A proposed classification for peri-implantitis. The International journal of periodontics \& restorative dentistry $\mathbf{3 2}, 533$ 540.

Giannobile, W. V. (2012) Salivary diagnostics for periodontal diseases. Journal of the American Dental Association 143, 6S-11S.

Giannobile, W. V., Beikler, T., Kinney, J. S., Ramseier, C. A., Morelli, T. \& Wong, D. T. (2009) Saliva as a diagnostic tool for periodontal disease: current state and future directions. Periodontology 2000 50, 52-64. doi:10.1111/j.1600-0757.2008.00288.x.

Giannobile, W. V., McDevitt, J. T., Niedbala, R. S. \& Malamud, D. (2011) Translational and clinical applications of salivary diagnostics. Advances in dental research 23, 375-380. doi:10.1177/0022034511420434.

Gmur, R., Strub, J. R. \& Guggenheim, B. (1989) Prevalence of Bacteroides forsythus and Bacteroides gingivalis in subgingival plaque of prosthodontically treated patients on short recall. Journal of periodontal research 24, 113-120.

Guncu, G. N., Akman, A. C., Gunday, S., Yamalik, N. \& Berker, E. (2012) Effect of inflammation on cytokine levels and bone remodelling markers in periimplant sulcus fluid: a preliminary report. Cytokine 59, 313-316. doi:10.1016/j.cyto.2012.04.024. 
Haffajee, A. D., Socransky, S. S., Patel, M. R. \& Song, X. (2008) Microbial complexes in supragingival plaque. Oral microbiology and immunology 23, 196-205. doi:10.1111/j.1399-302X.2007.00411.x.

Heitz-Mayfield, L. J. (2008) Peri-implant diseases: diagnosis and risk indicators. Journal of clinical periodontology 35, 292-304. doi:10.1111/j.1600051X.2008.01275.x.

Khoshkam, V., Chan, H. L., Lin, G. H., MacEachern, M. P., Monje, A., Suarez, F., Giannobile, W. V. \& Wang, H. L. (2013) Reconstructive procedures for treating peri-implantitis: a systematic review. Journal of dental research 92, 131S-138S. doi:10.1177/0022034513509279.

Kigure, T., Saito, A., Seida, K., Yamada, S., Ishihara, K. \& Okuda, K. (1995) Distribution of Porphyromonas gingivalis and Treponema denticola in human subgingival plaque at different periodontal pocket depths examined by immunohistochemical methods. Journal of periodontal research 30, 332-341.

Kinney, J. S., Morelli, T., Braun, T., Ramseier, C. A., Herr, A. E., Sugai, J. V., Shelburne, C. E., Rayburn, L. A., Singh, A. K. \& Giannobile, W. V. (2011) Saliva/pathogen biomarker signatures and periodontal disease progression. Journal of dental research 90, 752-758. doi:10.1177/0022034511399908.

Kinney, J. S., Morelli, T., Oh, M., Braun, T. M., Ramseier, C. A., Sugai, J. V. \& Giannobile, W. V. (2014) Crevicular fluid biomarkers and periodontal disease progression. Journal of clinical periodontology 41, 113-120. doi:10.1111/jcpe.12194.

Kivela-Rajamaki, M., Maisi, P., Srinivas, R., Tervahartiala, T., Teronen, O., Husa, V., Salo, T. \& Sorsa, T. (2003) Levels and molecular forms of MMP-7 (matrilysin-1) and MMP-8 (collagenase-2) in diseased human periimplant sulcular fluid. Journal of periodontal research 38, 583-590.

Kumar, P. S., Mason, M. R., Brooker, M. R. \& O'Brien, K. (2012) Pyrosequencing reveals unique microbial signatures associated with healthy and failing dental implants. Journal of clinical periodontology 39, 425-433. doi:10.1111/j.1600-051X.2012.01856.x. 
Ma, J., Kitti, U., Teronen, O., Sorsa, T., Husa, V., Laine, P., Ronka, H., Salo, T., Lindqvist, C. \& Konttinen, Y. T. (2000) Collagenases in different categories of peri-implant vertical bone loss. Journal of dental research 79, 18701873.

Mandell, R. L. (1984) A longitudinal microbiological investigation of Actinobacillus actinomycetemcomitans and Eikenella corrodens in juvenile periodontitis. Infection and immunity 45, 778-780.

Melo, R. F., Lopes, B. M., Shibli, J. A., Marcantonio, E., Jr., Marcantonio, R. A. \& Galli, G. M. (2012) Interleukin-1beta and interleukin-6 expression and gene polymorphisms in subjects with peri-implant disease. Clinical implant dentistry and related research 14, 905-914. doi:10.1111/j.17088208.2010.00325.x.

Miller, C. S., King, C. P., Jr., Langub, M. C., Kryscio, R. J. \& Thomas, M. V. (2006) Salivary biomarkers of existing periodontal disease: a cross-sectional study. Journal of the American Dental Association 137, 322-329.

Mombelli, A. \& Decaillet, F. (2011) The characteristics of biofilms in peri-implant disease. Journal of clinical periodontology 38 Suppl 11, 203-213. doi:10.1111/j.1600-051X.2010.01666.x.

Mullally, B. H., Dace, B., Shelburne, C. E., Wolff, L. F. \& Coulter, W. A. (2000) Prevalence of periodontal pathogens in localized and generalized forms of early-onset periodontitis. Journal of periodontal research 35, 232-241.

Murata, M., Tatsumi, J., Kato, Y., Suda, S., Nunokawa, Y., Kobayashi, Y., Takeda, H., Araki, H., Shin, K., Okuda, K., Miyata, T. \& Yoshie, H. (2002) Osteocalcin, deoxypyridinoline and interleukin-1beta in peri-implant crevicular fluid of patients with peri-implantitis. Clinical oral implants research 13, 637643.

Nomura, T., Ishii, A., Shimizu, H., Taguchi, N., Yoshie, H., Kusakari, H. \& Hara, K. (2000) Tissue inhibitor of metalloproteinases-1, matrix metalloproteinases- 1 and -8, and collagenase activity levels in periimplant crevicular fluid after implantation. Clinical oral implants research 11, 430-440.

Nowzari, H., Phamduong, S., Botero, J. E., Villacres, M. C. \& Rich, S. K. (2012) The profile of inflammatory cytokines in gingival crevicular fluid around 
healthy osseointegrated implants. Clinical implant dentistry and related research 14, 546-552. doi:10.1111/j.1708-8208.2010.00299.x.

Ramseier, C. A., Kinney, J. S., Herr, A. E., Braun, T., Sugai, J. V., Shelburne, C. A., Rayburn, L. A., Tran, H. M., Singh, A. K. \& Giannobile, W. V. (2009) Identification of pathogen and host-response markers correlated with periodontal disease. Journal of periodontology $\mathbf{8 0}, 436-446$. doi:10.1902/jop.2009.080480.

Roos-Jansaker, A. M., Lindahl, C., Renvert, H. \& Renvert, S. (2006) Nine- to fourteen-year follow-up of implant treatment. Part II: presence of periimplant lesions. Journal of clinical periodontology 33, 290-295. doi:10.1111/j.1600-051X.2006.00906.x.

Salcetti, J. M., Moriarty, J. D., Cooper, L. F., Smith, F. W., Collins, J. G., Socransky, S. S. \& Offenbacher, S. (1997) The clinical, microbial, and host response characteristics of the failing implant. The International journal of oral \& maxillofacial implants 12, 32-42.

Salminen, A., Gursoy, U. K., Paju, S., Hyvarinen, K., Mantyla, P., Buhlin, K., Kononen, E., Nieminen, M. S., Sorsa, T., Sinisalo, J. \& Pussinen, P. J. (2014) Salivary biomarkers of bacterial burden, inflammatory response, and tissue destruction in periodontitis. Journal of clinical periodontology. doi:10.1111/jcpe.12234.

Salvi, G. E., Aglietta, M., Eick, S., Sculean, A., Lang, N. P. \& Ramseier, C. A. (2012) Reversibility of experimental peri-implant mucositis compared with experimental gingivitis in humans. Clinical oral implants research 23, 182190. doi:10.1111/j.1600-0501.2011.02220.x.

Saygun, I., Nizam, N., Keskiner, I., Bal, V., Kubar, A., Acikel, C., Serdar, M. \& Slots, J. (2011) Salivary infectious agents and periodontal disease status. Journal of periodontal research 46, 235-239. doi:10.1111/j.16000765.2010.01335.x.

Schierano, G., Pejrone, G., Brusco, P., Trombetta, A., Martinasso, G., Preti, G. \& Canuto, R. A. (2008) TNF-alpha TGF-beta2 and IL-1beta levels in gingival and peri-implant crevicular fluid before and after de novo plaque accumulation. Journal of clinical periodontology 35, 532-538. doi:10.1111/j.1600-051X.2008.01224.x. 
Sexton, W. M., Lin, Y., Kryscio, R. J., Dawson, D. R., 3rd, Ebersole, J. L. \& Miller, C. S. (2011) Salivary biomarkers of periodontal disease in response to treatment. Journal of clinical periodontology 38, 434-441. doi:10.1111/j.1600-051X.2011.01706.x.

Shelburne, C. E., Shelburne, P. S., Dhople, V. M., Sweier, D. G., Giannobile, W. V., Kinney, J. S., Coulter, W. A., Mullally, B. H. \& Lopatin, D. E. (2008) Serum antibodies to Porphyromonas gingivalis chaperone HtpG predict health in periodontitis susceptible patients. PloS one 3, e1984. doi:10.1371/journal.pone.0001984.

Smeets, R., Henningsen, A., Jung, O., Heiland, M., Hammacher, C. \& Stein, J. M. (2014) Definition, etiology, prevention and treatment of peri-implantitis a review. Head \& face medicine 10, 34. doi:10.1186/1746-160X-10-34.

Socransky, S. S., Haffajee, A. D., Cugini, M. A., Smith, C. \& Kent, R. L., Jr. (1998) Microbial complexes in subgingival plaque. Journal of clinical periodontology 25, 134-144.

Soell, M., Elkaim, R. \& Tenenbaum, H. (2002) Cathepsin C, matrix metalloproteinases, and their tissue inhibitors in gingiva and gingival crevicular fluid from periodontitis-affected patients. Journal of dental research $\mathbf{8 1}, 174-178$.

Syndergaard, B., Al-Sabbagh, M., Kryscio, R. J., Xi, J., Ding, X., Ebersole, J. L. \& Miller, C. S. (2014) Salivary biomarkers associated with gingivitis and response to therapy. Journal of periodontology 85, e295-303. doi:10.1902/jop.2014.130696.

Tamura, N., Ochi, M., Miyakawa, H. \& Nakazawa, F. (2013) Analysis of bacterial

flora associated with peri-implantitis using obligate anaerobic culture technique and 16S rDNA gene sequence. The International journal of oral \& maxillofacial implants 28, 1521-1529. doi:10.11607/jomi.2570.

Teles, R., Sakellari, D., Teles, F., Konstantinidis, A., Kent, R., Socransky, S. \& Haffajee, A. (2010) Relationships among gingival crevicular fluid biomarkers, clinical parameters of periodontal disease, and the subgingival microbiota. Journal of periodontology 81, 89-98. doi:10.1902/jop.2009.090397. 
Tomasi, C. \& Derks, J. (2012) Clinical research of peri-implant diseases--quality of reporting, case definitions and methods to study incidence, prevalence and risk factors of peri-implant diseases. Journal of clinical periodontology 39 Suppl 12, 207-223. doi:10.1111/j.1600-051X.2011.01831.X.

Xu, L., Yu, Z., Lee, H. M., Wolff, M. S., Golub, L. M., Sorsa, T. \& Kuula, H. (2008) Characteristics of collagenase- 2 from gingival crevicular fluid and periimplant sulcular fluid in periodontitis and peri-implantitis patients: pilot study. Acta odontologica Scandinavica 66, 219-224. doi:10.1080/00016350802183393.

Yager, P., Edwards, T., Fu, E., Helton, K., Nelson, K., Tam, M. R. \& Weigl, B. H. (2006) Microfluidic diagnostic technologies for global public health. Nature 442, 412-418. doi:10.1038/nature05064.

Zitzmann, N. U. \& Berglundh, T. (2008) Definition and prevalence of peri-implant diseases. Journal of clinical periodontology 35, 286-291. doi:10.1111/j.1600-051X.2008.01274.x.

\section{Footnotes:}

* RNAprotect ${ }^{\mathrm{TM}}$, Ambion, Austin, TX, USA

† Oralflow Inc., Smithtown, NY, USA

‡ Eppendorf AG, Hamburg, Germany

$\S$ Epicentre Biotechnologies, Madison, WI, USA

|| Life Technologies, Carlsbad, CA, USA

đI RayBiotech, Inc., Norcross, GA, USA

\section{Tables and figures}

Table 1. Patient and Implant Level demographic data 
Table 2. Biomarker profile from Peri-Implant Crevicular Fluid

Table 3. Microbial profile of subgingival plaque biofilm

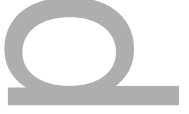

Table 4. Individual diagnostic ability of Selected PICF Biomarkers and Target Bacterial Species

Table 5. Paired diagnostic ability of Selected PICF Biomarkers and Target Bacterial Species

Figure 1. Average levels of selected biomarkers.

Table 1. Patient and Implant Level Demographic Data

\begin{tabular}{|c|c|c|c|}
\hline \multicolumn{2}{|c|}{ Variables } & \multirow{2}{*}{$\begin{array}{c}\text { Healthy } \\
\text { Group } \\
62.1(10.4)\end{array}$} & \multirow{2}{*}{$\begin{array}{c}\text { Peri-implantitis } \\
\text { Group } \\
65.3(10.3)\end{array}$} \\
\hline Age (years) & Mean (SD) & & \\
\hline \multirow{3}{*}{ Gender } & Male & $20(58.8 \%)$ & 15 (44.1\%) \\
\hline & Female & $14(41.2 \%)$ & 19 (55.9\%) \\
\hline & Non-smoker & $26(76.5 \%)$ & 17 (50.0\%) \\
\hline \multirow{2}{*}{ Smoking status } & Past & $8(23.5 \%)$ & $13(38.2 \%)$ \\
\hline & Current & $0(0 \%)$ & 4 (11.8\%) \\
\hline \multirow{2}{*}{ Implant Location } & Anterior & 7 (20.6\%) & $3(8.8 \%)$ \\
\hline & Posterior & 27 (79.4\%) & $31(91.2 \%)$ \\
\hline
\end{tabular}




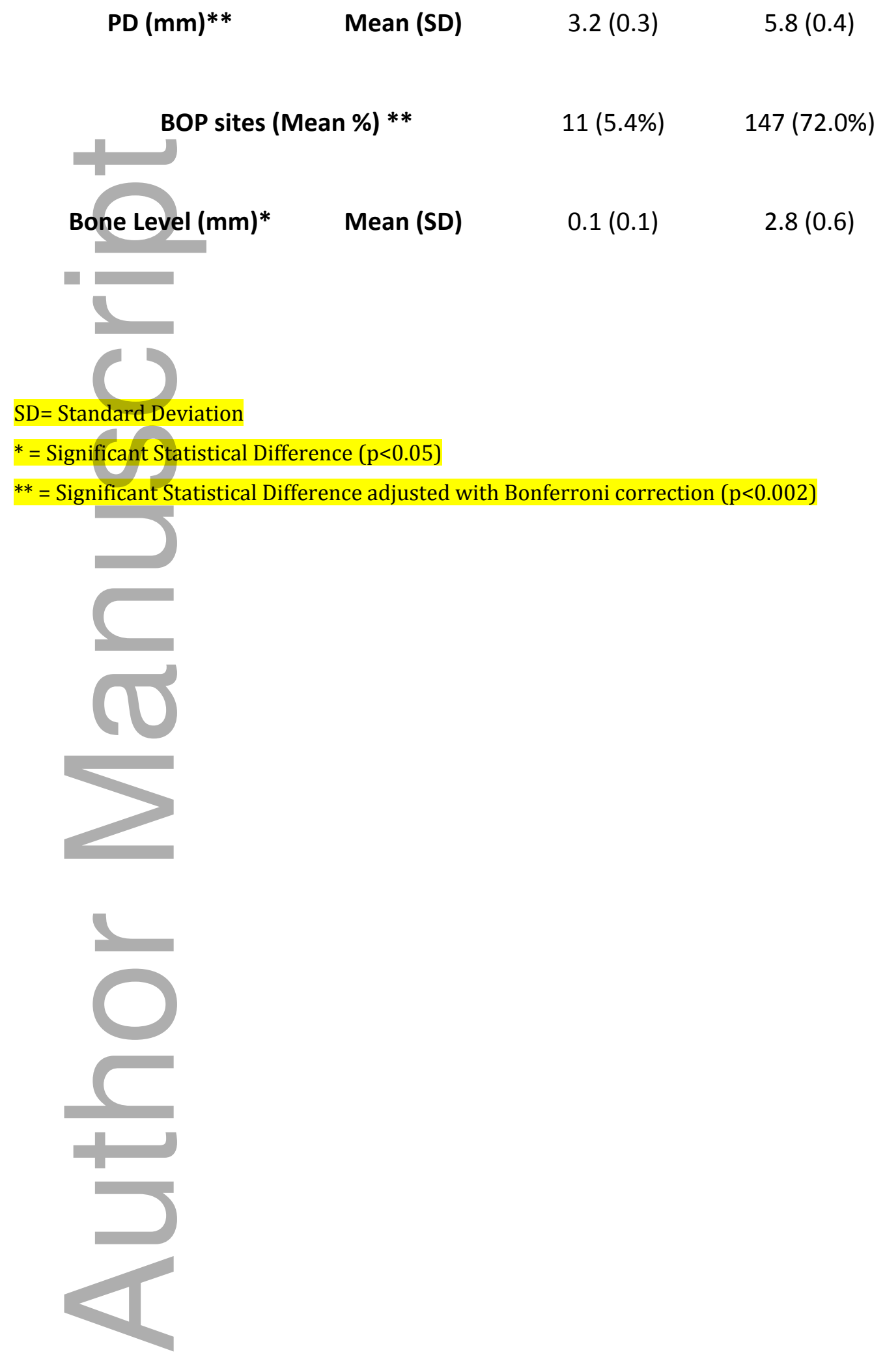

This article is protected by copyright. All rights reserved 
Table 2. Biomarker profile from Peri-Implant Crevicular Fluid

\begin{tabular}{|c|c|c|c|c|c|c|c|c|c|}
\hline \multirow{2}{*}{ Biomarker } & \multicolumn{4}{|c|}{ Healthy } & \multicolumn{4}{|c|}{ Peri-implantitis } & \multirow{2}{*}{$p$-value } \\
\hline & Mean (SD) & Q1 & Q2 & Q3 & Mean (SD) & Q1 & Q2 & Q3 & \\
\hline $\mathrm{IL}-1 \beta(\mathrm{pg} / \mathrm{ml})$ & $44.60(53.00)$ & 7.30 & 18.61 & 73.41 & $135.83(97.30)$ & 50.67 & 111.76 & 209.84 & $<0.001^{* *}$ \\
\hline MMP-8 (pg/ml) & $6029.18(2132.07)$ & 4618.56 & 6632.35 & 73911.80 & $5943.13(1183.24)$ & 5224.93 & 5950.50 & 6567.84 & 0.454 \\
\hline OPG (pg/ml) & $66.51(115.1)$ & 0.31 & 10.56 & 70.54 & $111.69(159.00)$ & 21.31 & 58.22 & 147.70 & 0.050 \\
\hline TIMP-2 (pg/ml) & $5488.32(3852.5)$ & 2737.70 & 4888.23 & 8932.21 & $9771.82(5113.00)$ & 4572.10 & 10565.68 & 13877.55 & $0.001 * *$ \\
\hline
\end{tabular}




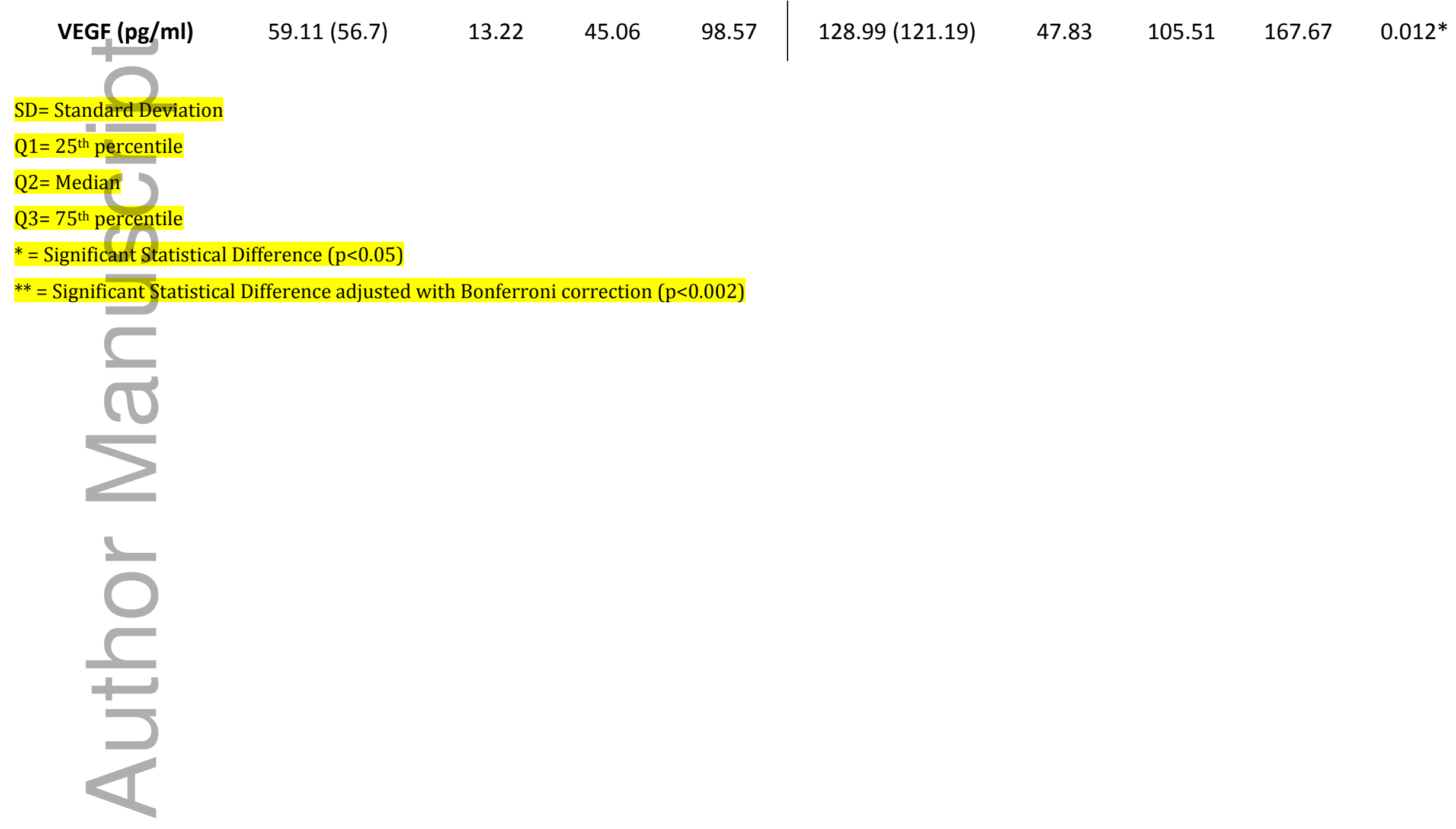

This article is protected by copyright. All rights reserved 
Table 3. Microbial profile of subgingival plaque biofilm

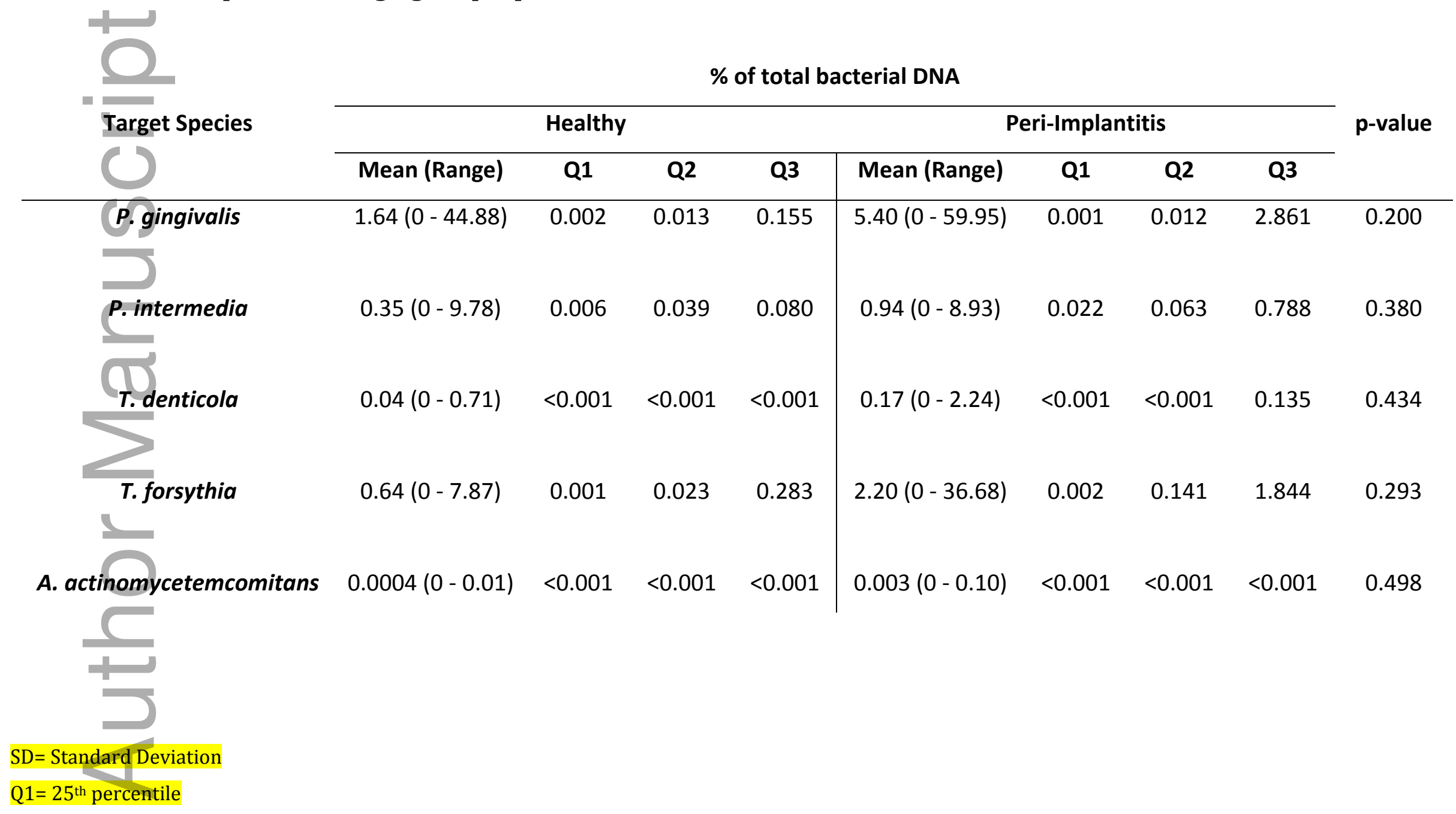


Q2= Median

$\mathrm{Q} 3=75^{\text {th }}$ percentile

* = Significant Statistical Difference $(\mathrm{p}<0.05)$

** = Significant Statistical Difference adjusted with Bonferroni correction $(\mathrm{p}<0.002)$

Table 4. Individual diagnostic ability of Selected PICF Biomarkers and Target Bacterial Species

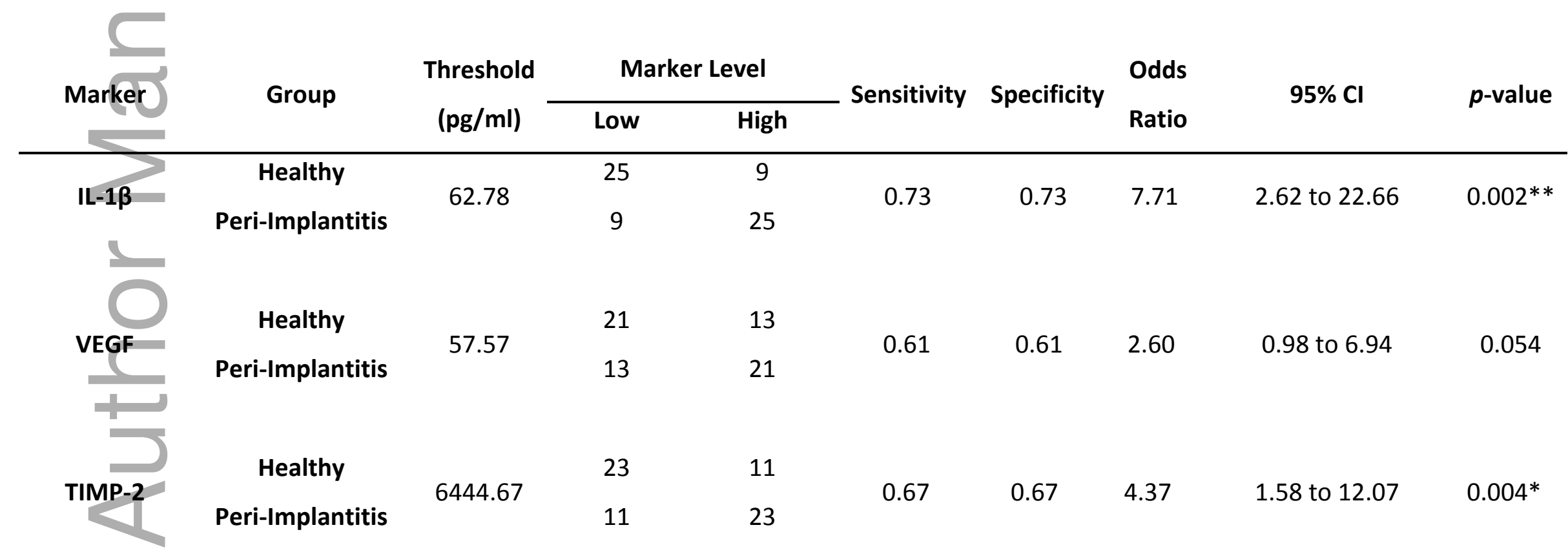

This article is protected by copyright. All rights reserved 


\begin{tabular}{|c|c|c|c|c|c|c|c|c|c|}
\hline T. denticola & $\begin{array}{c}\text { Healthy } \\
\text { Peri-Implantitis }\end{array}$ & 0.001 & $\begin{array}{l}29 \\
19\end{array}$ & $\begin{array}{c}5 \\
15\end{array}$ & 0.75 & 0.60 & 4.57 & 1.42 to 14.69 & $0.010^{*}$ \\
\hline T. for & $\begin{array}{l}\text { Healthy } \\
\text { Peri-Implantitis }\end{array}$ & 0.07 & $\begin{array}{l}20 \\
15\end{array}$ & $\begin{array}{l}14 \\
19\end{array}$ & 0.57 & 0.57 & 1.80 & 0.69 to 4.73 & 0.226 \\
\hline P. gingi & $\begin{array}{l}\text { Healthy } \\
\text { Peri-Implantitis }\end{array}$ & 0.01 & $\begin{array}{l}18 \\
17\end{array}$ & $\begin{array}{l}16 \\
17\end{array}$ & 0.51 & 0.48 & 1.12 & 0.43 to 2.91 & 0.808 \\
\hline
\end{tabular}

This article is protected by copyright. All rights reserved 
Table 5. Combined diagnostic ability of Selected PICF Biomarkers and Target Bacterial Species

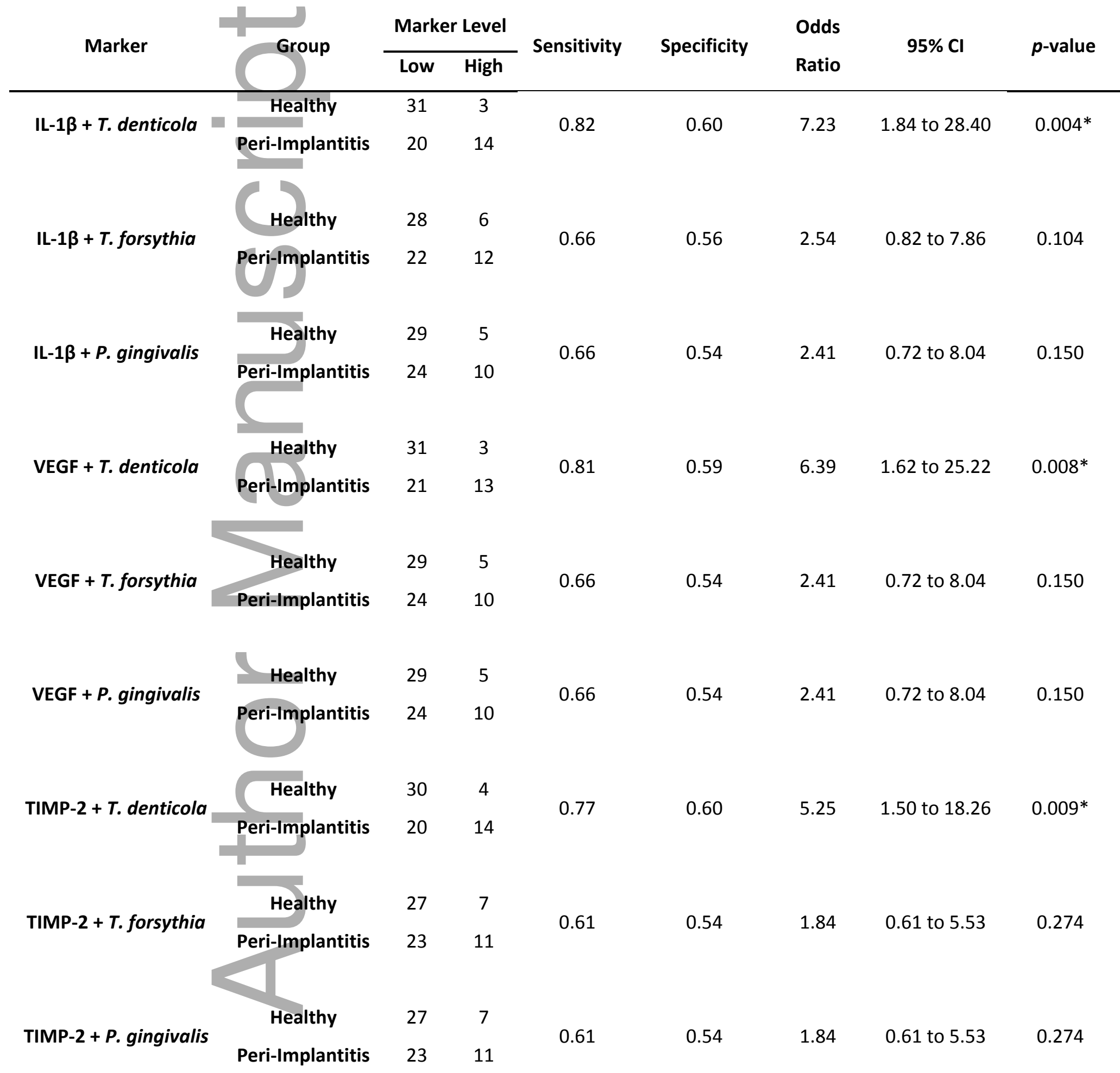


* = Significant Statistical Difference $(\mathrm{p}<0.05)$

** = Significant Statistical Difference adjusted with Bonferroni correction $(\mathrm{p}<0.002)$
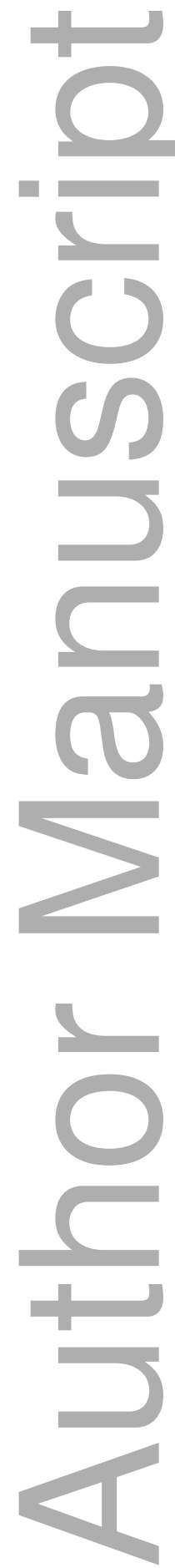

This article is protected by copyright. All rights reserved 

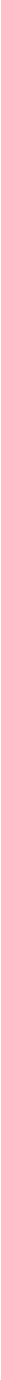

Bars represent Meann and Standared Devidtion values

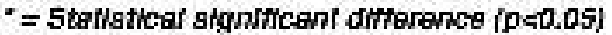
"N = Stalistical significant difference with Borthrort correction ( $p=0.002)$ clr_12708_f1.tiff

This article is protected by copyright. All rights reserved 